\title{
Role of alcohol in the development and progression of hepatocellular carcinoma
}

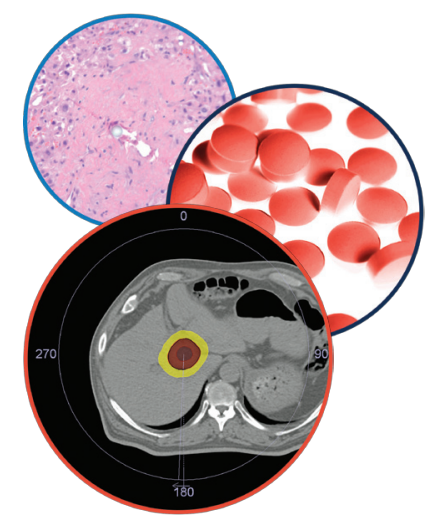

Hepatic Oncology

\author{
Iain H McKillop ${ }^{* 1}$, Laura W Schrum² \& Kyle J Thompson'
}

Hepatocellular carcinoma (HCC) is a significant cause of cancer-related morbidity and mortality. Chronic, heavy ethanol consumption is a major risk for developing the worsening liver pathologies that culminate in hepatic cirrhosis, the leading risk factor for developing HCC. A significant body of work reports the biochemical and pathological consequences of ethanol consumption and metabolism during hepatocarcinogeneis. The systemic effects of ethanol means organ system interactions are equally important in understanding the initiation and progression of HCC within the alcoholic liver. This review aims to summarize the effects of ethanol-ethanolmetabolism during thepathogenesis ofalcoholicliverdisease, theprogression toward HCC and the importance of ethanol as a comorbid factor for HCC development.

Submitted: 19 May 2015; Accepted: 22 October 2015; Published online: 30 November 2015

\section{Practice points}

- Hepatocellular carcinoma (HCC) arises predominantly as a result of exposure to known risk factors that include viral hepatitis infection, chronic, heavy ethanol consumption and obesity.

- Ethanol is classified as a carcinogen and acts synergistically with other risk factors in developing the underlying liver diseases that give rise to HCC.

- The widespread use and abuse of ethanol makes understanding the biochemical, genetic and cellular effects of ethanol within the liver central to our understanding of the progressively worsening pathogenesis that occur in the progression of alcoholic liver disease toward hepatic cirrhosis and HCC.

- Changes in HCC patient demographics bring a new urgency to understanding how obesity and ethanol may act and interact as independent and/or comorbid risk factors in liver pathogenesis.

Hepatocellular carcinoma (HCC) is the most common primary malignancy of the liver and ranks as the fifth most commonly diagnosed cancer in the world [1,2]. Late detection and the aggressive nature of HCC contrive to limit the treatment options available to patients making HCC the second leading cause of cancer-related mortality [1]. The etiology of HCC differs from that of many other common solid tumors in that it is based primarily on exposure to known risk factors, in the absence of familial patterns, and these risk factors are often geographically stratified. For

'Department of Surgery, Carolinas Medical Center, Charlotte, NC 28203 USA

${ }^{2}$ Department of Medicine, Carolinas Medical Center, Charlotte, NC 28203 USA

*Author for correspondence: Tel.: +1 704355 2619, Fax: +1 704355 7202; iain.mckillop@carolinashealthcare.org

\section{KEYWORDS}

- alcohol - DNA adducts

- hepatocellular carcinoma (HCC) • reactive oxygen species (ROS) • Sirtuin-1 (Sirt-1)

Future $\because$ Medicine ${ }_{\text {part of }}$ 
example, viral hepatitis $\mathrm{B}$ and/or $\mathrm{C}$ infection (HBV/HCV) underlie $75 \%$ of all $\mathrm{HCC}$ cases worldwide. In Asia-Pacific and sub-Saharan African countries $\mathrm{HBV}$ is the dominant viral risk factor while $\mathrm{HCV}$ infection is more common in western countries [3]. Similarly, exposure to aflatoxins (naturally occurring mycotoxins from Aspergillus) is a significant risk factor for HCC in regions of high humidity and poor grain storage (many of which also have high HBV infection rates) but is rare in western countries.

Although HCV is a significant etiological factor in developed nations, chronic high ethanol consumption and obesity are regarded as the leading causes of HCC development in the western hemisphere $[4,5]$. Despite clear differences in the nature of these risk factors, a common thread following exposure is the progressive worsening of hepatic pathologies toward cirrhosis, an endstage liver disease characterized by regenerative nodules of hepatocytes in the heavily fibrotic or scarred liver. Independent of underlying etiology, an estimated $80-90 \%$ of HCC cases arise in the setting of cirrhosis [6]. Cirrhosis is marked by a reduction in the proliferative (regenerative) capacity of liver, shortening of telomeres and chronic activation of numerous oncogenic signaling pathways including c-Met, Wnt/ $\beta$-catenin and phosophtidolinosiitol-3-kinase/Akt to promote tumorigenesis in cirrhotic liver [7-9].

Risk factors for HCC can also act synergistically, such that the risk for developing HCC is significantly elevated in the presence of two (or more) of these factors. For example patients with viral hepatitis alone experienced a 19.1 relative risk (RR) of HCC compared with a $2.4 \mathrm{RR}$ for ethanol consumption. However, patients with viral hepatitis infection with alcohol consumption experienced an RR of 53.9 for HCC development [10-13]. Donato et al. reported similar findings wherein a 'dose-dependent' relationship was observed between ethanol consumption and hepatitis virus infection, with greater risk being observed in HCV-positive patients versus HBVpositive patients [14]. While HCC is most closely linked to the development of cirrhosis regardless of etiology (cases of HCC due to ethanol consumption in the absence of cirrhosis are rare), progression rates to HCC do differ among cirrhotics with differing underlying etiologies. One possible explanation in the case of alcoholic liver disease (ALD) is the number of patients who succumb to liver failure due to alcoholic hepatitis, an acute liver injury with high short-term mortality and limited treatment options, whereas cirrhosis in setting of hepatitis $\mathrm{C}$ is a more progressive liver injury with fewer patient deaths due to fulminant hepatic injury [15].

While significant advances have been made in diagnosing and treating many other common cancers, the prognosis for HCC remains dismal, 5-year survival rates of 15-20\% being commonly reported, a rate that has changed little over the last three decades [2,3]. The poor outcomes for HCC patients are directly linked to late diagnosis due to a lack of obvious presenting symptoms, a failure to identify reliable early biomarkers of disease progression from cirrhosis to HCC, and economic challenges in deploying effective treatment strategies in countries with the highest exposure to risk factors [16]. Current treatment for HCC is heavily reliant on surgical intervention via ablation, resection and/or organ transplant $[17,18]$. As a result, the prognosis for HCC patients is substantially improved for those treated with curative ablation and surgical resection modalities. For these patients, 5-year survival rates approach 50\% [18], while 5-year survival for patients receiving orthotopic liver transplantation (OLT) is reported to be as high as $80 \%[19,20]$. However, late detection and advanced disease staging, concomitant with a lack of transplantable organs or disease that has progressed outside Milan criteria, often limit the availability of these therapeutic approaches [21].

Despite the bleak prognosis for patients with HCC, substantial progress has been made in reducing the burden of disease associated with viral hepatitis. Global deployment of the hepatitis $B$ vaccine and approval of new hepatitis $C$ regiments of ledipasvir and sofosbuvir (>90\% cure rate for genotype I hepatitis $\mathrm{C}$ patients) will likely reduce the number of cases of $\mathrm{HCC}$ in the future. However, the continued presence of alcohol, changes in drinking patterns in western culture and a growing incidence of ethanol consumption and abuse in developing nations means cases of HCC due to underlying cirrhosis from ALD are likely to rise. This article aims to provide a timely summary of the mechanisms by which alcohol promotes the underlying liver disease in which HCC typically arises, and the role alcohol plays during hepatocyte transformation. Finally, we seek to describe some of the novel areas of current and future clinical and translational research that will allow us to better understand the role of alcohol in the pathogenesis of HCC. 
Ethanol as a risk factor for cancer

In 1988, the International Agency for Research on Cancer (IARC) identified ethanol as a cancer-causing agent and listed a causal relationship between ethanol consumption and cancers of the digestive tract, liver and breast [22]. Subsequently, the World Health Organization (WHO) identified consumption of ethanol as one of the top ten global risks for worldwide disease burden, with global ethanol consumption estimated at $13 \mathrm{~g} /$ day for approximately 2 billion people [23]. These estimates, coupled with increased case-controlled and cohort studies, led to the Group 1 designation of ethanol - carcinogenic in humans - at the 2009 IARC monograph meeting [23]. Heavy drinkers (> 50 $\mathrm{g} /$ day) of ethanol exhibited a $>2.5$-fold increases in relative risk (RR) for esophageal, laryngeal, pharyngeal and oral cancers, as well as 1.4-fold and 1.5-fold increases in risk for liver and colorectal cancers, respectively [24-27]. The findings with liver cancer should be taken with caution however, as ethanol clearly promotes liver cirrhosis, a pathology in which $80-90 \%$ of HCCs evolve [28]. Development and diagnosis of cirrhosis may lead to cessation or reduction in drinking, complicating the establishment of a direct relationship between liver disease and ethanol [29]. A meta-analysis of the association between light drinking $(<12.5 \mathrm{~g} /$ day $)$ and cancer also reveals increased $\mathrm{RR}$ for oral and pharyngeal (1.17), esophageal (1.30), liver (1.03) and breast (1.05) cancers, albeit at markedly reduced levels compared with sustained, heavy drinking [30].

Experimentally, ethanol administration is reported as a mechanism for carcinogenesis, including liver tumors. Addition of ethanol to drinking water (alternating 10\%/20\% [v/v]) of female ICR mice promoted increased papillary and medullary breast carcinomas compared with animals not consuming ethanol over a 25 -month period [31]. Shorter-term administration (10 weeks) of $15 \% / 20 \%[v / v]$ ethanol in the drinking water of male MIN, multiple intestinal neoplasia; heterozygous mutation of the APC gene, mice promoted increased gastrointestinal tumors compared with control mice [32]. Lifetime administration (104 weeks) of $2.5 \% / 5.0 \%[v / v]$ ethanol in the drinking water of $\mathrm{B} 6 \mathrm{C} 3 \mathrm{~F} 1$ mice led to development of hepatocellular adenoma and HCCs in male mice compared with controls [33]. Studies using a strain of ethanol-preferring $(\mathrm{P})$ rats given free access to drinking water or $10 \%[\mathrm{v} / \mathrm{v}]$ ethanol in drinking water demonstrated increased liver tumors compared with $\mathrm{P}$ rats provided drinking water alone [34]. Ethanol consumption is also reported to enhance progression of liver hepatomas of male, but not female, B6C3F1 mice administered with diethylnitrosamine (DEN) at 3 weeks of age and given 10/20\% ethanol in drinking water ( $v / v$, alternate days) over the final 8 weeks of a 48-week study [35].

\section{Absorbtion \& metabolism of ethanol}

The metabolism of ethanol following acute or moderate consumption outside of the chronic liver setting primarily occurs via ADH. Human $\mathrm{ADH}$ s are zinc-containing metalloenzymes comprising two $40-\mathrm{kDa}$ peptides that form either homo- or heterodimers. The metabolism of ethanol by $\mathrm{ADH}$ is a reversible, $\mathrm{NAD}^{+}$-dependent reaction in which ethanol is oxidized to acetaldehyde concomitant with production of $\mathrm{NADH}$, the reduced form of $\mathrm{NAD}^{+}$. Acetaldehyde is then rapidly and irreversibly metabolized to acetate via ALDH, an enzyme primarily expressed in hepatocytes. Like ADH metabolism, $\mathrm{NAD}^{+}$is reduced by ALDH to NADH as a cofactor during acetaldehyde metabolism (Figure 1).

To date seven isozymes of ADH have been identified across five classes, with different classes of ADH grouped according to their physical and biochemical properties [36]; Class I ADHs are pyrazole-sensitive $\mathrm{ADHs}$ and are composed of their constituent subunits (ADH1A-ADH1A; $A D H 1 B-\mathrm{ADH}_{1} \mathrm{~B}^{*} 1, \mathrm{ADH}_{1} \mathrm{~B}^{*} 2$ and $\mathrm{ADH} 1 \mathrm{~B}^{*} 3$; $A D H 1 C-A D H 1 C$, and $\left.\mathrm{ADH} 1 C^{*} 1-\mathrm{ADH}_{1} \mathrm{C}^{*} 2\right)$. Class I ADHs are predominant in the liver and are responsible for the majority of ethanol metabolism following acute-moderate ethanol consumption [37]. Considerable diversity exists among Class I ADHs with respect to affinity and capacity for ethanol. For instance, $\beta 1$ subunits have high affinity $\left(K_{m} 0.05 \mathrm{mM}\right)$ and low capacity $\left(V_{\max } 9 \mathrm{~mol} / \mathrm{s}\right)$ for ethanol, whereas $\beta 3$ subunits have low affinity $\left(K_{m} 34 \mathrm{mM}\right)$ and high activity $\left(V_{\max } 300 \mathrm{~mol} / \mathrm{s}\right)$ for ethanol [38,39]. Class II $\mathrm{ADH}(A D H 2$, old nomenclature $A D H 4$; homodimer, $\pi \pi$ polypeptides) is expressed primarily in liver and has activity toward ethanol, particularly in the intoxicated state, due to its high $K_{m}[39]$. Class III ADH ( $A D H 3$, old nomenclature $A D H 5$; homodimer, $\chi \chi$ polypeptides) is expressed in liver, stomach and intestine and was historically reported to exert higher activity toward ethanol metabolism [40]. However, studies with ADH3 knockout (-/-) mice 


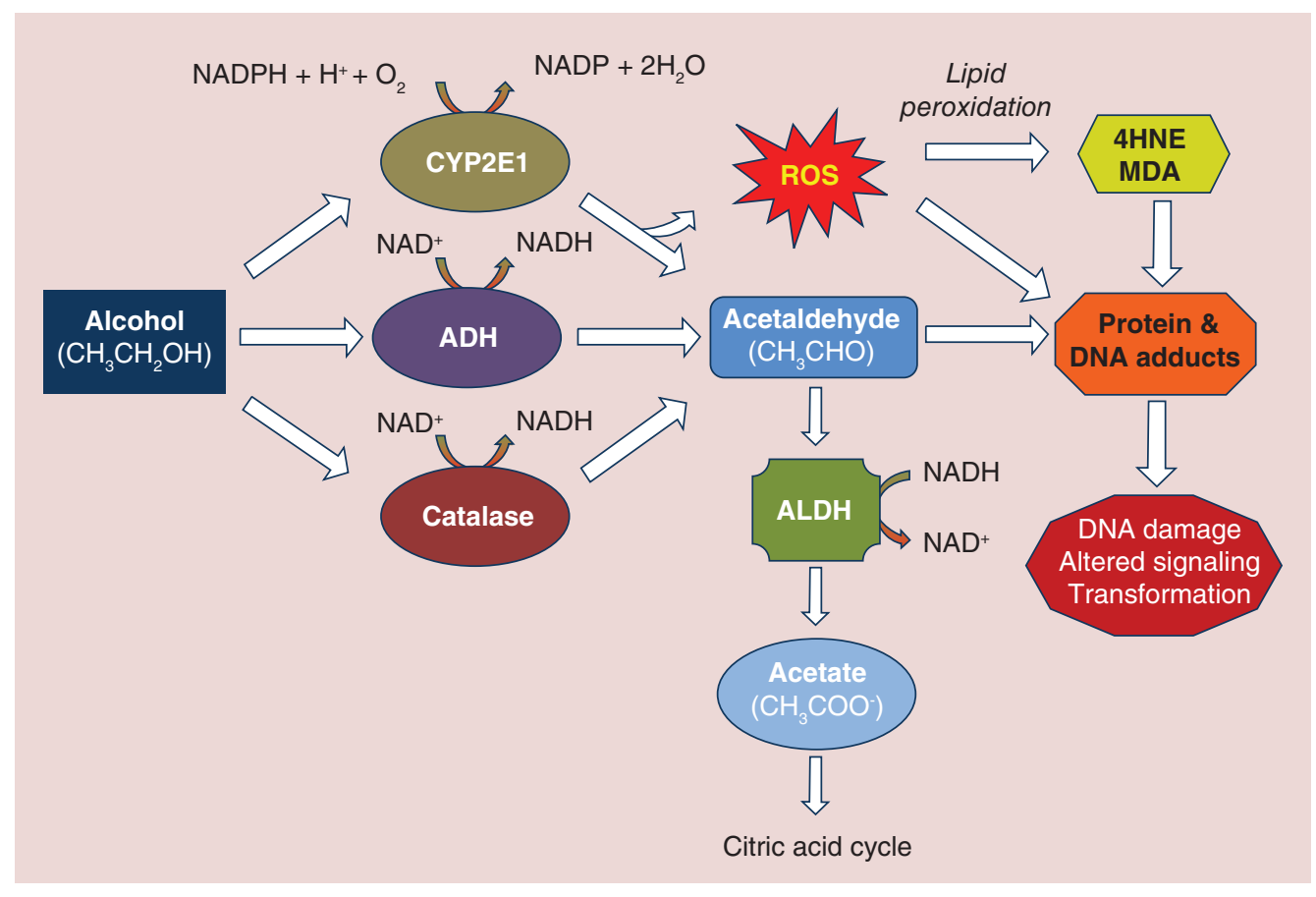

Figure 1. Schematic diagram illustrating major hepatic ethanol metabolism pathways. 4HNE: 4-Hydroxynonenal; ADH: Alcohol dehydrogenase; ALDH: Aldehyde dehydrogenase; CYP2E1: Cytochrome P450 2E1; MDA: Malondialdhyde; ROS: Reactive oxygen species.

demonstrated diminished ability to metabolize ethanol following acute exposure, suggesting a role for $\mathrm{ADH} 3$ in metabolizing ethanol via first-pass metabolism (gastric) and high ethanol consumption (liver) [41]. Although several ADH forms have been implicated in cancers of the aerodigestive tract, only one study to our knowledge describes elevated risk for HCC development amongst heavy drinkers with the ADH1C*1 allele [42], suggesting ADH genotype has limited significance in predicting or mediating susceptibility to developing HCC.

\section{Cytochrome P4502E1 (CYP2E1) \& ethanol metabolism}

Metabolism of ethanol in individuals who are chronic, heavy ethanol consumers utilizes nonADH pathways including peroxisomal catalaze and microsomal enzymes. Components of the microsomal ethanol oxidizing system (MEOS), particularly, are important for ethanol metabolism during hepatocarcinogenesis. Several members of the cytochrome P450 (CYP) family of enzymes, including CYP1A2 and CYP3A4, can contribute to the oxidation of ethanol; however, CYP2E1 is the central effector of the MEOS and is expressed primarily in hepatocytes and mucosal cells lining the GI tract [43].
Following sustained, heavy ethanol consumption, CYP2E1 is induced by a 4-10-fold upregulation of CYP2E1 expression at the mRNA and protein levels. Induction of CYP2E1 can occur within 1 week of $40 \mathrm{~g} /$ day consumption of ethanol [44]. Following cessation of chronic/regular ethanol consumption, an equally rapid decline in CYP2E1 expression is reported [44]. In the intermittent state of ethanol consumption, the MEOS is a minor contributor to ethanol metabolism with approximately $10 \%$ of total ethanol oxidation being attributable to CYP2E1 [45]. However, in settings of chronic high levels of ethanol consumption, CYP2E1 can account for more than $30 \%$ of ethanol oxidation.

Metabolism of ethanol by CYP2E1, like $\mathrm{ADH}$, generates acetaldehyde (Figure 1). However, differences between P450 family members and $\mathrm{ADH}$ include the requirement for oxygen activation by $\mathrm{P} 450$ for catalytic function and production of NADP through NADPH oxidation [46]. This necessary activation step can result in the production of reactive oxygen species (ROS) by the uncoupling of the catalytic cycle, producing superoxide anion radical $\left(\mathrm{O}_{2}{ }^{-}-\right)$or hydrogen peroxide $\left(\mathrm{H}_{2} \mathrm{O}_{2}\right)$, as opposed to oxidation of substrates such as ethanol [46]. ROS have been implicated in a wide range of 
pathological states including alcoholic liver disease (ALD) and hepatocarcinogenesis. Other sources of ROS, such as the lipid peroxidation products 4-hydroxynonenal (4-HNE) and malondialdehyde, are also attributed to CYP2E1 activity following sustained, heavy ethanol consumption [47]. The formation of these biologically reactive aldehyde molecules can interact with DNA bases to form exocyclic DNA adducts such as $1, \mathrm{~N}^{6}$-ethenodeoxyadenosine and $3, \mathrm{~N}^{4}$ ethenodeoxycytidine, the result of which can be the promotion of potentially carcinogenic DNA mutations [48].

CYP2E1 can also metabolize a wide range of other (potentially) carcinogenic substrates including procarcinogens such as nitrosamines found in tobacco products, azo-compounds, and halogenated hydrocarbons found in many industrial processes [49,50]. Of particular relevance to hepatocarcinogenesis is the metabolism of retinol by CYP2E1. Retinoic acids are metabolized by CYP2E1 to produce pro-apoptotic polar retinoic metabolites, which (among other effects) act to abrogate mitochondrial membrane potential [51]. Retinoic acid levels are important for maintaining cellular differentiation, and their depletion can promote cellular regeneration and proliferation, likely through activation of the AP-1 transcriptional complex, an important feature in the development of both cirrhosis and neoplasia [52,53]. The involvement of CYP2E1 in promoting ethanol-induced hepatic oxidative stress and carcinogenesis is supported by in vitro data, as well as in vivo studies utilizing CYP2E1 knockout mice and the CYP2E1 inhibitor chlormethiazole [54]. Although CYP2E1 polymorphisms have been identified, currently available data do not indicate a connection between variations in these CYP2E1 phenotypes and liver cancer among ethanol drinkers [55].

\section{Acetaldehyde, adduct formation \& hepatocarcinogenesis}

Acetaldehyde, the metabolic product of ethanol oxidation, is listed as an IARC Group 1 carcinogen when "associated with the consumption of alcoholic beverages" and a Group 2b carcinogen when considered alone. The metabolism of acetaldehyde to acetate is catalyzed by ALDH, for which 19 genes have been identified to date in humans. ALDH1 and ALDH2 are highly expressed in liver and account for the rapid clearing of acetaldehyde following ethanol oxidation (Figure 1). One key mutated form of ALDH2,
ALDH $2 * 2$, is characterized by a substitution of lysine for glutamate at position 487. Individuals homozygous for $\mathrm{ALDH}_{2}{ }^{2}$ have negligible ALDH activity, whereas those heterozygous for the allele have reduced activity [56].

Acetaldehyde is carcinogenic via several mechanisms. First, acetaldehyde can form DNA adducts, such as $\mathrm{N}^{2}$-ethyl-2'-deoxyguanosine ( $\mathrm{N}^{2}$-ethyl-dG). Although $\mathrm{N}^{2}$-ethyl-dG can form stable lesions with DNA, it appears to be more of a marker for ALD rather than mutagenic, as DNA polymerase can effectively bypass the mutated base to incorporate deoxycytidine into the complementary strand [57,58]. In addition to $\mathrm{N}^{2}$-ethyl-dG, acetaldehyde can produce other, more potentially carcinogenic, DNA lesions such as $1, \mathrm{~N}^{2}$-propano-2'-deoxyguanosine $\left(1, \mathrm{~N}^{2}\right.$ PdG). 1, $\mathrm{N}^{2}-\mathrm{PdG}$ lesions appear to be dependent on the steady-state form of DNA to which they are bound. In the single-stranded form, $1, \mathrm{~N}^{2}-$ PdG adducts exist in a cyclic form that is likely mutagenic [59]. These adducts can also exist in the open ring conformation in double-stranded DNA, which, in turn, exposes another aldehyde moiety that can react to form more complex lesions, such as DNA-protein or DNA-DNA linkages [60].

Acetaldehyde can also form adducts with proteins by interacting with the $\varepsilon$ - or $\alpha$-amino group of lysine or $\mathrm{N}$-terminal amino acids [61]. For example, acetaldehyde adducts of $\mathrm{O}^{6}$ methylguanine transferase, an enzyme involved in repair of DNA adducts, can directly impair its activity, potentially mediating carcinogenesis [62]. Adducts can also form between acetaldehyde and glutathione (GSH), the main intracellular antioxidant protein, which inhibits GSH activity against $\mathrm{H}_{2} \mathrm{O}_{2}$ and potentiates the effects of lipid peroxidation and ROS generation by CYP2E1 metabolism of ethanol [63].

Adducts form and accumulate preferentially in zone 3 (perivenous zone) of the hepatic lobule, corresponding to the location of early ethanol-induced liver injury, and are associated with increases in aminotransferases, markers of hepatocellular injury [64]. Chronic accumulation of adducts is linked to development of reactive antibodies and can promote autoimmune attacks on the affected hepatocytes and non-parenchymal cells [65].

Defects in acetaldehyde clearance are implicated in the promotion of cancers associated with ethanol consumption. For example, individuals expressing the ALDH2*2 phenotype 
lack activity toward acetaldehyde, resulting in acetaldehyde accumulation following ethanol ingestion. The ALDH2*2 phenotype exhibits distinct geographical distribution, which results in the allele being present in nearly $50 \%$ of the eastern Asian population, while being virtually absent in western populations. Of equal note, individuals possessing the $\mathrm{ADH} 1 \mathrm{~B}^{*} 2$ phenotype have a metabolic activity toward ethanol that is 40-times greater than those with the ADH1B*1 or $\mathrm{ADH}_{1} \mathrm{~B}^{*} 3$ phenotype and are characterized by rapid, persistent accumulation of acetaldehyde [66]. In this instance, acetaldehyde accumulation is presumed to protect individuals against alcohol abuse and/or dependence as the noxious, unpleasant effects associated with acetaldehyde accumulation prevent frequent, sustained ethanol consumption. However, should individuals with the $\mathrm{ADH}_{1 \mathrm{~B}} * 2$ phenotype persist with alcohol consumption, an accumulation of markers of acetaldehyde exposure, such as $\mathrm{N}^{2}$-ethyl-dG, occurs. This is likely to explain the increased incidence of esophageal squamous cell carcinoma in the eastern Asian population among moderate-to-heavy drinkers, in which this phenotype is most common [67]. Furthermore, increases in risk for liver cancer are reported among moderate-to-heavy drinkers possessing either the ALDH2*1 or ALDH2*2 versus ALDH1*1 phenotype $[68,69]$.

Ethanol, methylation \& cancer

Methylation of DNA is an important regulator of gene activity and is frequently dysregulated in cancer [70]. DNA methylation occurs by transfer of a methyl group to the carbon 5 position of deoxycytidines, most frequently when positioned immediately upstream of deoxyguanosines (CpG dinucleotide). Clusters of $\mathrm{CpG}$ dinucleotides are termed $\mathrm{CpG}$ islands and are frequently observed in the promoter region of genes where they tend to be unmethylated, or in large regions of repeated DNA such as centromeres or retrotransposons [71].

DNA methyltransferases (DNMTs) mediate DNA methylation by transfer of a methyl group from s-adenosyl-L-methionine (SAMe) to DNA and production of s-adenosylhomocysteine (SAH) [72]. SAH is an important mediator of DNA methylation, as it is a strong competitive inhibitor of methyltransferases, including DNMTs [73]. DNMTs are made up of three key enzymes; DNMT1, which is responsible for methylation of hemimethylated DNA following DNA replication, and DNMT3A and DNMT3B, which are involved in de novo methylation [74]. For subsequent methylation reactions, the pool of methyl donors (i.e., SAMe) must be maintained. Regeneration of SAMe occurs by transfer of ATP to methionine by methionine adenosyltransferases (MATs).

Ethanol consumption perturbs several steps in the generation of SAMe and maintenance of methylation status. Alcohol-dependent individuals are frequently malnourished and exhibit impaired uptake and availability of key factors important in 1-carbon (1-C) metabolism, which limits methionine availability and is likely to be responsible, at least in part, for the diminished SAMe levels reported in this population [75]. For instance, patients who chronically consume ethanol frequently have reduced levels of folate, an important source of dietary methyl group equivalents [76]. Regeneration of methionine from homocysteine, which is produced by removal of adenosine from $\mathrm{SAH}$, can also be impaired by ethanol consumption, an event that impairs methionine synthase activity [77]. In the liver, ethanol can disrupt methionine conversion to SAMe by inhibiting MAT activity, while DNMT3A and DNMT3B activity is reduced in alcoholic subjects compared with nonalcoholic controls [78].

Methylation defects are directly implicated in HCC development, including those caused by ethanol [79]. Genome-wide hypomethylation is reported in HCC with increasing levels of hypomethylation linked to worsening prognoses, independent of underlying etiology [79,80]. In an experimental rat model, administration of SAMe prevented the size and frequency of preneoplastic lesions, as well as progression to tumors concomitant with restoration of DNA methylation $[81,82]$. However, a review of SAMe for treatment of ALD failed to reveal significant benefit, although SAMe may be of therapeutic value in preventing progression to HCC [82].

Oxidative stress, nonparenchymal cells \& the gut-liver axis

ALD is a complex disease arising from both direct and indirect consequences of ethanol consumption. Ingestion of ethanol is associated with overgrowth of bacteria in the gut compared with nondrinkers, as evidenced in both animal models and human studies; in cirrhotic patients this overgrowth correlates with severity of disease [83-85]. Ethanol metabolism by 
gut microbiota can lead to acetaldehyde accumulation as a result of low intestinal expression of ALDHs. Acetaldehyde has been shown to increase gut permeability toward bacterial products such as lipopolysaccharide (LPS) and peptidoglycans via redistribution of zona occludens- 1 and disrupting tight junction integrity [85]. Evidence for gut-derived products contributing to ALD was demonstrated by administration of antibiotics to rodents fed ethanol, which resulted in significantly reduced injury [86].

As has been addressed, ethanol metabolism is associated with oxidative stress through the generation of ROS, particularly by CYP2E1 in the setting of chronic, heavy ethanol consumption. Oxidative stress is an important characteristic in the development and progression of ALD [87,88]. Concomitant with oxidative stress is the reduction in levels and/or activities of endogenous antioxidants to counteract these stressors [89]. Selective depletion of mitochondrial stores of GSH are reported following administration of ethanol, with replenishment linked to disruption of GSH transporters from mitochondrial delivery of cytosolic GSH [90].

Prolonged oxidative stress by ROS is associated with the activation of non-parenchymal cells such as Kupffer cells and hepatic stellate cells, death of hepatocytes and development of fibrosis, the precursor condition to cirrhosis. Hepatocyte oxidative stress promotes mitochondrial dysfunction, depletion of endogenous antioxidants and sensitization to cell death mediators, particularly TNF- $\alpha$ [91,92]. When considered in combination with the effect of chronic heavy ethanol consumption on increasing gut permeability and circulating levels of gut-derived endotoxin, this can act to stimulate nicotinamide adenine dinucleotide phosphate (NADPH)-oxidase and ROS production in Kupffer cells [93]. Ethanol feeding also increases the sensitivity of Kupffer cells to circulating levels of endotoxin and leads to enhanced TNF- $\alpha$ production [94]. This connection between ethanol, endotoxin, NADPH oxidase and TNF- $\alpha$ production was highlighted in a study in which pretreatment with diphenyliodonium (an inhibitor of NADPH oxidase) reduced ROS generation and TNF- $\alpha$ production in Kupffer cells of ethanol-fed rats [95]. Signals and ROS mediators from Kupffer cells and hepatocytes can elicit a phenotype change in hepatic stellate cells from quiescent vitamin-A storing cells to activated myofibroblast-like effector cells that deposit excessive ECM (e.g., type I collagen) and promote fibrosis $[96,97]$.

Although a clear effect of oxidative stress exists on the development of ALD, the therapeutic benefit from antioxidants remains to be established. Animal studies have frequently demonstrated improved pathology from antioxidant administration concomitant with ethanol feeding; however, these agents have frequently failed in human trials [98]. Interestingly, silibinin, an antioxidant derived from milk thistle, was reported to worsen HCC progression when combined with ethanol in male mice. This finding was surprising given the hepatoprotective effects of silibinin in other models of injury, and underscores the importance of carefully vetting purported therapeutics for ALD, including antioxidants [99].

\section{SIRTUIN-1, steatosis \& inflammation}

Sirtuins (named for yeast Sir2, silent matingtype information regulation 2) are $\mathrm{NAD}^{+}-$ dependent deacetylases with broad biological activity. Sirt1 is implicated in regulating diverse intracellular processes such as DNA repair, apoptosis, inflammation and energy production. In liver cells, Sirt1 can act as a metabolic 'sensor,' depending on energy levels, to regulate lipogenesis, gluconeogenesis and inflammation according to activity state. Sirt 1 activity is controlled by the balance of $\mathrm{NAD}^{+} / \mathrm{NADH}$ and the $\mathrm{NAD}^{+}$degradation product, nicotinamide [100]. Impaired Sirt1 activity promotes the maintenance of target acetylation status, including SREBP-1c and NF- $\kappa \mathrm{B}$, thereby promoting transcription of their target genes and impairs the transcriptional co-activation of proliferatoractivated receptor gamma coactivator 1- $\alpha$.

Ethanol consumption is reported to diminish both Sirt1 activity and expression, and to promote lipogenesis and inflammation [101-103]. These studies were confirmed by genetic deletion of Sirt1, which greatly exacerbated injury in mouse livers following ethanol intake [104]. Resveratrol, a stilbenoid found in the skin of grapes and other berries, has been identified as an activator of Sirt1, and administration of resveratrol ameliorated ethanol-induced liver injury and nonalcoholic fatty liver in mice $[105,106]$.

Although Sirt1 appears to be a promising target for preventing ALD, the role of Sirt1 in the progression of HCC and other cancers is more controversial. Sirt1 expression is reported to be upregulated in HCC, and silencing of 
Sirt1 in HCC cell lines decreases proliferation in vitro [107-109]. The analysis of Sirt1 expression in a DEN model of HCC identified distinct roles for Sirt1 in normal liver, early carcinogenesis and late/severe HCC, in which increases in Sirt1 were limited to early stages of HCC resulting from decreased HDAC1/C/EBP- $\beta$ complex activity [110]. Despite the apparent association between Sirt1 expression and HCC, the precise mechanistic link(s) by which Sirt1 impacts HCC development and/or progression remain to be fully elucidated.

Studies using pharmacological activators of Sirtl activity report impaired HCC proliferation concomitant with findings that the Sirt1 activity inhibitor, EX-527, promoted HCC proliferation in vitro, which suggests that changes in Sirt1 activity are more important that changes in expression levels per se [111]. In addition to its possible role in hepatic tumor cell proliferation, Sirt1 has been implicated in the regulation of DNA repair proteins such as Ku70, and deletion of Sirt1 is associated with genomic instability and increased chromosomal fusions [112]. Conversely, a Sirt1 transgenic mouse model has been reported to exhibit a lower incidence of cancer and decreased DNA damage when employed in a model of metabolic syndrome associated cancers [113]. To date, no studies have been reported in which Sirt-1 deficient mice have been used in models of liver cancer, which presents an interesting opportunity to further refine the role of Sirt1 in liver carcinogenesis and/or HCC progression.

Hepatic steatosis is the accumulation of fat droplets within hepatocytes and can be either microvesicular (small intracellular fat vacuoles) or macrovesicular (large droplets that distort the hepatocyte nucleus). Steatosis can arise from chronic alcohol consumption or obesity and metabolic disorders, and while the etiology of steatosis may differ, the histological features of steatosis are nearly indistinguishable regardless of cause. Ethanol promotes hepatic steatosis via several mechanisms including the change in redox status and accumulation of NADH that results from ethanol metabolism. This signals an energy-rich state within hepatocytes, leading to diminished Sirtl activity, which in turn promotes de novo lipogenesis and diminishing $\beta$-oxidation through downstream targets such as SREBP-1c [101,114]. Ethanol consumption can also promote hepatic steatosis through upregulation of CD-36, a scavenger of long-chain fatty acids, oxidized lipids and lipoproteins. Experimental data with CD-36-deficient mice demonstrated abolition of steatosis with mice fed a low fat/high carbohydrate version of the Lieber-DeCarli diet (36\% kcal\% ethanol) [115] .

Steatosis due to chronic ethanol consumption can progress to alcoholic steatohepatitis (ASH), a pathology characterized by inflammation and fibrosis. Ethanol can promote progression to ASH by both direction of action on parenchymal cells, nonparenchymal cells and the gutliver axis. Exposure of Kupffer cells to ethanol potentiates sensitivity to LPS, which is elevated by ethanol consumption due to increased gut permeability to gram-negative bacteria [16]. Activation of Kupffer cells increases oxidative stress and secretion of inflammatory cytokines which can act on hepatocytes, as well as stimulating the activation of HSCs to produce excessive ECM products and leading to fibrosis [117]. Inflammation can be further promoted by diminution of Sirt1 activity by ethanol, promoting increased acetylation and activity of NF- $\mathrm{kB}$.

\section{Ethanol \& liver cancer progression}

Hepatocellular carcinoma is a multistep disease of initiation, promotion and progression that (typically) develops over a period of decades. Considerable advances have been made in understanding the role of ethanol and ethanol metabolism in the pathogenesis of ALD and the progression toward hepatic cirrhosis and HCC. The impact of alcohol on HCC progression following initial hepatocyte transformation is an area that has received less attention than the role of ethanol-ethanol metabolism in hepatocyte transformation. Epidemiological data indicate alcohol-abusing patients exposed to other risk factors for HCC exhibit increased risk for developing HCC $[10,118]$. However, fewer studies have addressed the impact of moderate, but sustained, alcohol consumption in patients exposed to similar risk factors. This may prove particularly important in western countries with the identification of obesity as an independent risk factor for developing HCC and the high incidence of ethanol (ab) use and obesity in these countries. For example, in the USA, $34 \%$ of the population has a $\mathrm{BMI}>30$, and 178 million individuals consumed some alcohol in the past 12 months $[119,120]$. Out of these, 58 million individuals exhibited 'dangerous drinking behavior,' and 28 million were 'alcohol dependent' [121].

The presence of alcohol in the liver has the 
potential to affect tumor progression at multiple levels. The hepatic vasculature is derived from the hepatic artery and partially deoxygenated blood from the portal vein. This unique physiological-vascular arrangement means the liver is particularly susceptible to hypoxia and tumor progression is dependent on neoangiogenesis, the majority of HCCs deriving their blood supply from arterial sources. VEGF is frequently overexpressed in HCC and promotes angiogenesis in a variety of disease state models. Previous studies suggest alcohol exposure can enhance VEGF expression in the liver to promote HCC progression [122]. Ethanol metabolism is also associated with decreased retinoic acid stores and increased proliferation, factors that have been linked experimentally with increased VEGF expression.

In vitro models have had mixed success in establishing a link between ethanol consumption and HCC progression compared with control HCC models. Using rat hepatoma cells, ethanol challenge was associated with ERK1/2 phosphorylation and increased proliferation [123]. However, in a separate study utilizing human HepG2 cells, ethanol exposure was cytotoxic not proproliferative [124]. Interestingly, ethanol metabolism is often impaired in HCC cell lines because of low expression of $\mathrm{ADH}$ and CYP2E1 [125]. However, following stable transfection of HepG2 cells with ADH, CYP2E1 or $\mathrm{ADH}$ and CYP2E1 enzymes combined, ethanol exposure $(25 \mathrm{mM})$ failed to alter cell proliferation despite adequate ethanol metabolism and production of oxidative stressors and acetaldehyde [125]. In a separate study, comparison between rat hepatoma cells and freshly isolated hepatocytes indicated that transformed cells treated with ethanol exhibited increased mitogenesis and upregulation of $\mathrm{G}_{\mathrm{i}}$-protein expression, effects that were not observed in primary hepatocytes [126]. Taken together, these data suggest that, while in vitro studies are useful in elucidating the mechanisms of ethanol metabolism and subsequent cell stress, disparate results on readouts such as proliferation indicate substantial differences exist between cell lines. Given the multi-tissue targets of ethanol toxicity, in vivo approaches to study ethanol-mediated HCC progression would likely be more accurate.

Animal studies using male and female $\mathrm{B} 6 \mathrm{C} 3$ mice initiated with neonatal DEN exposure and treated with an ethanol regimen for 8 weeks at 40 weeks of age showed an increased number and size of HCC lesions in male, but not female mice, compared with those treated only with DEN [35]. These effects were observed in concert with oxidative stress and impairment of the endogenous antioxidant system. These findings contradicted those found by a similar, but not identical, approach using male B6 mice to examine interactions between ethanol and obesity in promoting HCC. Ethanol in combination with DEN failed to generate significant differences in tumor growth and multiplicity compared with DEN alone. The same lack of promotion occurred when comparing obesity + DEN with the obesity + ethanol + DEN group. It is important to note that in the obesity and DEN groups, the mice were extremely tumor burdened and moribund, and it is possible that no further progression was possible by addition of ethanol. However, this would not explain why ethanol plus DEN failed to promote HCC tumor progression compared with DEN alone [127]. Other studies using xenograph tumor models support a role for ethanol in promoting HCC progression. Implantation of HepG2 cells in nude mice led to enhanced tumor growth when combined with consumption of $2 \%$ ethanol in drinking water, compared with drinking water alone. This effect was mediated, at least in part by NF- $\kappa B$, as treatment with pyrrolidine dithiocarbamate abolished this effect and reduced ethanol-mediated angiogenesis [128]. The same investigators showed ethanol consumption was associated with worsened TNM stage, increased vessel invasion and poorer prognosis compared with nondrinkers after controlling for underlying etiology, age, sex and underlying cirrhosis [128].

\section{Conclusion \& future perspective}

Hepatocellular carcinoma remains a significant global health burden for which no major improvements in treatments or outcomes have emerged in the last 40 years [1-3]. While the incidence of HCC attributable to HBV and/or $\mathrm{HBC}$ infection might be predicted to decline as a result of improved vaccination and antiviral therapies, these efforts are not without limitations. Cost remains a significant potential barrier, both to the treatment of existing $\mathrm{HCV}$ infection with new antiviral therapies and, making affordable, widespread HBV vaccination programs available to areas with the highest rates of infection - areas that are also among the most economically challenged. Of equal importance, particularly in the USA and Western Europe, is the ominous increase in obesity along with 
the identification of obesity as an independent risk factor for $\mathrm{HCC}[4,5,10]$. Given the continued global prevalence of ethanol use and abuse, and the multifaceted-multiorgan sites that alcohol exerts pathogenic effects, it is of clear interest to continue to understand the mechanisms by which ethanol consumption affects normal physiological function and disease initiation and progression.

At the biochemical and cellular level, there is a continuing need to employ and develop in vitro models to better understand the effects of ethanol on signaling and genetic mechanisms that regulate transformation and subsequent tumorgenicity. Such approaches are likely to be particularly important as they can be performed independently of the complex intracellular interactions that occur intrahepatically and systemically. Such an approach allows the rapid analyses of exposure to different amounts of ethanol over different time periods. While several excellent models exist to study these pathways, the emergence of obesity as a risk factor for HCC raises intriguing possibilities for developing innovative in vitro models to study the effects of ethanol in transformed and nontransformed 'obese' cells with phenotypes similar to those observed in vivo. Indeed, the equally multicellular/multiorgan response toward obesity may demand such models if we are to understand alterations in the complex cellular networks in obese and/or ethanol challenged cells.

While isolated cell systems are important experimental tools, they can equally be limited by a lack of appropriate 'controls' (due to hepatocyte dedifferentiation in culture [129]) and the absence of a multicellular/systemic environment. Improvements in hepatocyte culture models may go some way to address these issues [129,130], as could ex vivo isolated organ perfusion systems [131] and 'liver slice' models [132,133]. While such ex vivo models have been used to study the effect of ethanol on liver function [134-136], to date they have not been widely employed to study the effects of ethanol on HCC function within the liver per se.

While in vitro and ex vivo models are likely to play a central role in understanding the pathogenesis of HCC development and progression at the cellular level, there is little doubt of the continued need to study the hepatic effects of ethanol at the whole organism, in vivo level. The use of appropriate models to study the role of ethanol in ALD and HCC has been a subject of continued debate and controversy [137,138]. In particular there are no known, reliable rodent models that accurately mimic human disease state progression from hepatosteatosis, through fibrosis and cirrhosis to HCC development and progression [137]. Of interest, the most recent models of ALD based on chronic ethanol feeding followed by binge administration report greater similarities to human HCC and it will be of particular interest to see how this model evolves and is employed by ethanol-ALD-HCC researchers [139].

In preparing this review we were cognizant that attempting to prepare an 'all encompassing' alcohol-HCC review would leave as many areas inadequately addressed as could be covered. For this reason we focused on alcohol metabolism, obesity and Sirt1 as areas of particular interest. However, numerous other areas of research opportunity are equally likely to provide valuable insight into our understanding of ALD and the factors that affect progression to HCC that include;

\section{- MicroRNAs \& ALD-HCC}

Significant advances are being made in our understanding of the role of noncoding miRNAs as important factors in hepatic disease development and progression [140,141]. While many of the initial studies have focused on the regulation of viral-associated liver disease, an increasing body of work is addressing how ethanol affects miRNA expression and function $[142,143]$.

\section{- Epigenetics \& ethanol}

As our understanding of genetic regulation continues to expand it is becoming increasingly apparent that chronic exposure to environmental agents such as ethanol directly impacts epigenetic regulation. Understanding the mechanisms of these processes (e.g., histone modification), is likely to be highly significant in understanding susceptibility to ALD progression to HCC [144-146].

\section{- Immune responses \& ALD-HCC}

The identification of the gut-liver axis as a central mediator in the intra- and extrahepatic immune responses to chronic, heavy ethanol consumption has led to tremendous advances in our understanding of the importance of the immune system during the initiation and progression of ALD [147-150]. As we enter a new era of immunotherapy in treating other common 
cancers it is enticing to speculate that using some of these agents to study ALD may reveal equally intriguing data regarding the immune system responses following alcohol ingestion.

\section{- Obesity as a cofactor in ALD \& HCC}

As the threat from $\mathrm{HCV} / \mathrm{HBV}$ diminishes in western society, it seems unavoidable that it will be replaced by obesity as a leading risk factor for hepatic disease [2-5]. Given the incidence of alcohol consumption and obesity it seems equally inevitable that understanding how these factors interact is essential if we are to prevent a surge in HCC incidence in an ever younger patient population.

\section{- Neural regulation of ALD-HCC}

Understanding the processes and events that underlie patterns of alcohol consumption and addiction are of clear significance in developing effective procedures to reduce or alter dangerous drinking patterns. Equally interesting are the data emerging to suggest other roles for the brain during the development of ALD and/or progression toward HCC. These include direct evidence for ethanol affecting the interaction between neural networks and the liver [151,152], effects of ethanol on circadian rhythms and neural pathways/hormonal patterns [153] and the effects of alcohol metabolism on neuronal signaling and subsequent alcohol consumption.

\section{Financial \& competing interests disclosure}

The authors have no relevant affiliations or financial involvement with any organization or entity with a financial interest in or financial conflict with the subject matter or materials discussed in the manuscript. This includes employment, consultancies, honoraria, stock ownership or options, expert testimony, grants or patents received or pending, or royalties.

We would like to thank Dr Jennifer C. Barnes for her assistance with preparing and editing the manuscript.

\section{References}

Papers of special note have been highlighted as:

- of interest; $\bullet$ of considerable interest

1 Torre LA, Bray F, Siegel RL, Ferlay J, Lortet-Tieulent J, Jemal A. Global cancer statistics, 2012. CA. Cancer J. Clin. 65(2), 87-108 (2015).

2 Venook AP, Papandreou C, Furuse J, De Guevara LL. The incidence and epidemiology of hepatocellular carcinoma: a global and regional perspective. Oncologist 15(Suppl. 4), 5-13 (2010).

3 Bosetti C, Turati F, La Vecchia C. Hepatocellular carcinoma epidemiology. Best Pract. Res. Clin. Gastroenterol. 28(5), 753-770 (2014).

4 Stickel F. Alcoholic cirrhosis and hepatocellular carcinoma. Adv. Exp. Med. Biol. 815, 113-130 (2015).

5 Vanni E, Bugianesi E. Obesity and liver cancer. Clin. Liver Dis. 18(1), 191-203 (2014).

- An important article highlighting the significance of obesity on liver health and subsequent risk for developing hepatocellular carcinoma (HCC). Explores emerging mechanisms that might underlie both NALFD and progression toward HCC.

6 Forner A, Llovet JM, Bruix J. Hepatocellular carcinoma. Lancet 379(9822), 1245-1255 (2012).

7 Delhaye M, Louis H, Degraef C et al.
Relationship between hepatocyte proliferative activity and liver functional reserve in human cirrhosis. Hepatology 23(5), 1003-1011 (1996).

8 Wege $\mathrm{H}$, Brummendorf TH. Telomerase activation in liver regeneration and hepatocarcinogenesis: Dr. Jekyll or Mr. Hyde? Curr. Stem Cell Res. Ther. 2(1), 31-38 (2007).

9 Farazi PA, Glickman J, Jiang S, Yu A, Rudolph KL, Depinho RA. Differential impact of telomere dysfunction on initiation and progression of hepatocellular carcinoma. Cancer Res. 63(16), 5021-5027 (2003).

10 Loomba R, Yang HI, Su J et al. Synergism between obesity and alcohol in increasing the risk of hepatocellular carcinoma: a prospective cohort study. Am. J. Epidemiol. 177(4), 333-342 (2013).

11 Ko WH, Chiu SY, Yang KC, Chen HH. Diabetes, hepatitis virus infection and hepatocellular carcinoma: a case-control study in hepatitis endemic area. Hepatol. Res. 42(8), 774-781 (2012).

12 Hassan MM, Hwang LY, Hatten CJ et al. Risk factors for hepatocellular carcinoma: Synergism of alcohol with viral hepatitis and diabetes mellitus. Hepatology 36(5), 1206-1213 (2002).

13 Monga SP. Role of wnt/beta-catenin signaling in liver metabolism and cancer. Int. J. Biochem. Cell Biol. 43(7), 1021-1029 (2011). Donato F, Tagger A, Gelatti U et al. Alcohol and hepatocellular carcinoma: the effect of lifetime intake and hepatitis virus infections in men and women. Am. J. Epidemiol. 155(4), 323-331 (2002).

15 Mathurin P, Bataller R. Trends in the management and burden of alcoholic liver disease. J. Hepatol. 62 (Suppl. 1), S38-S46 (2015).

- An important article addressing the significance of alcoholic liver disease in healthcare and how these patients are currently diagnosed and managed clinically. Also offers critical opinion of the relative merits and failures of these approaches.

16 El-Serag HB. Hepatocellular carcinoma. $N$. Engl. J. Med. 365(12), 1118-1127 (2011).

17 Seshadri RM, Besur S, Niemeyer DJ et al. Survival analysis of patients with stage $i$ and ii hepatocellular carcinoma after a liver transplantation or liver resection. $H P B$ (Oxford) 16(12), 1102-1109 (2014).

18 Neimeyer DJ, Simo KA, Iannitti DA, Mckillop IH. Ablation therapy for hepatocellular carcinoma: past, present and future perspectives. Hepatic Oncol. 1(1), 67-79 (2014).

19 Pawlik TM, Esnaola NF, Vauthey JN. Surgical treatment of hepatocellular carcinoma: similar long-term results despite geographic variations. Liver Transpl. 10 (2 Suppl. 1), S74-S80 (2004).

20 Patel MS, Kohn R, Kratz JR, Shah JA, Markmann JF, Vagefi PA. The race to liver transplantation: a comparison of patients with 
and without hepatocellular carcinoma from listing to post-transplantation. J. Am. Coll. Surg. 220 (6), 1001-1007 (2015).

21 Earl TM, Chapman WC. Hepatocellular carcinoma: resection versus transplantation. Semin. Liver Dis. 33(3), 282-292 (2013).

22 Iarc monographs on the evaluation of carcinogenic risks to humans. Alcohol. IARC Monogr. Eval. Carcinog. Risks Hum. 44, 1-416 (1988).

23 Baan R, Straif K, Grosse Y et al. Carcinogenicity of alcoholic beverages. Lancet Oncol. 8(4), 292-293 (2007).

24 Turati F, Garavello W, Tramacere I et al. A meta-analysis of alcohol drinking and oral and pharyngeal cancers. Part 2: results by subsites. Oral Oncol. 46(10), 720-726 (2010).

25 Islami F, Fedirko V, Tramacere I et al. Alcohol drinking and esophageal squamous cell carcinoma with focus on light-drinkers and never-smokers: a systematic review and meta-analysis. Int. J. Cancer 129(10), 2473-2484 (2011).

26 Fedirko V, Tramacere I, Bagnardi V et al. Alcohol drinking and colorectal cancer risk: an overall and dose-response meta-analysis of published studies. Ann. Oncol. 22(9), 1958-1972 (2011).

27 Corrao G, Bagnardi V, Zambon A, La Vecchia C. A meta-analysis of alcohol consumption and the risk of 15 diseases. Prev. Med. 38(5), 613-619 (2004).

28 Rehm J, Samokhvalov AV, Shield KD. Global burden of alcoholic liver diseases. J. Hepatol. 59(1), 160-168 (2013).

-• Important and timely analysis of the morbidity and mortality associated with alcohol use and abuse with particular emphasis on the contribution of alcoholic liver disease exerts.

29 Bagnardi V, Blangiardo M, La Vecchia C, Corrao G. A meta-analysis of alcohol drinking and cancer risk. Br. J. Cancer 85(11), 1700-1705 (2001).

30 Bagnardi V, Rota M, Botteri E et al. Light alcohol drinking and cancer: a meta-analysis. Ann. Oncol. 24(2), 301-308 (2013).

31 Watabiki T, Okii Y, Tokiyasu T et al. Long-term ethanol consumption in icr mice causes mammary tumor in females and liver fibrosis in males. Alcohol. Clin. Exp. Res. 24(Suppl. 4), S117-S122 (2000).

32 Roy HK, Gulizia JM, Karolski WJ, Ratashak A, Sorrell MF, Tuma D. Ethanol promotes intestinal tumorigenesis in the min mouse. Multiple intestinal neoplasia. Cancer Epidemiol. Biomarkers Prev. 11(11),
1499-1502 (2002).

33 Beland FA, Benson RW, Mellick PW et al. Effect of ethanol on the tumorigenicity of urethane (ethyl carbamate) in b6c3f1 mice. Food Chem. Toxicol. 43(1), 1-19 (2005).

34 Yip-Schneider MT, Doyle CJ, Mckillop IH et al. Alcohol induces liver neoplasia in a novel alcohol-preferring rat model. Alcohol. Clin. Exp. Res. 35(12), 2216-2225 (2011).

- Experimental paper reporting alcohol acts as a carcinogen in the absence of additional hepatic insult in rats that prefer alcohol when provided free choice. Of further interest, these animals develop HCC in the absence of underlying cirrhosis or other notable pathologies normally associated with chronic, heavy alcohol consumption in humans.

35 Brandon-Warner E, Walling TL, Schrum LW, Mckillop IH. Chronic ethanol feeding accelerates hepatocellular carcinoma progression in a sex-dependent manner in a mouse model of hepatocarcinogenesis. Alcohol. Clin. Exp. Res. 36(4), 641-653 (2012).

36 Duester G, Farres J, Felder MR et al. Recommended nomenclature for the vertebrate alcohol dehydrogenase gene family. Biochem. Pharmacol. 58(3), 389-395 (1999).

37 Jornvall H, Hoog JO. Nomenclature of alcohol dehydrogenases. Alcohol Alcohol 30(2), 153-161 (1995).

38 Crabb DW, Matsumoto M, Chang D, You M. Overview of the role of alcohol dehydrogenase and aldehyde dehydrogenase and their variants in the genesis of alcohol-related pathology. Proc. Nutr. Soc. 63(1), 49-63 (2004).

39 Lee SL, Chau GY, Yao CT, Wu CW, Yin SJ. Functional assessment of human alcohol dehydrogenase family in ethanol metabolism: significance of first-pass metabolism. Alcohol. Clin. Exp. Res. 30(7), 1132-1142 (2006).

40 Pares X, Vallee BL. New human liver alcohol dehydrogenase forms with unique kinetic characteristics. Biochem. Biophys. Res. Commun. 98(1), 122-130 (1981).

41 Haseba T, Duester G, Shimizu A, Yamamoto I, Kameyama K, Ohno Y. In vivo contribution of class III alcohol dehydrogenase (adh3) to alcohol metabolism through activation by cytoplasmic solution hydrophobicity. Biochim. Biophys. Acta 1762(3), 276-283 (2006).

42 Homann N, Stickel F, Konig IR et al. Alcohol dehydrogenase $1 \mathrm{c}^{*} 1$ allele is a genetic marker for alcohol-associated cancer in heavy drinkers. Int. J. Cancer 118(8), 1998-2002 (2006).
- Important study that analyzes alcohol dehydrogenase $(\mathrm{ADH})$ genotype and risk for alcohol-related pathologies, including HCC in a (relatively) large patient cohort of 818 subjects.

43 Lieber CS. Cytochrome p-4502e1: Its physiological and pathological role. Physiol. Rev. 77(2), 517-544 (1997).

44 Oneta CM, Lieber CS, Li J et al. Dynamics of cytochrome p4502el activity in man: Induction by ethanol and disappearance during withdrawal phase. J. Hepatol. 36(1), 47-52 (2002).

45 Lieber CS. The discovery of the microsomal ethanol oxidizing system and its physiologic and pathologic role. Drug Metab. Rev. 36(3-4), 511-529 (2004).

46 Lewis DF, Pratt JM. The p450 catalytic cycle and oxygenation mechanism. Drug Metab. Rev. 30 (4), 739-786 (1998).

47 Aleynik SI, Leo MA, Aleynik MK, Lieber CS. Increased circulating products of lipid peroxidation in patients with alcoholic liver disease. Alcohol. Clin. Exp. Res. 22(1), 192-196 (1998).

48 El Ghissassi F, Barbin A, Nair J, Bartsch H. Formation of 1,n6-ethenoadenine and 3,n4-ethenocytosine by lipid peroxidation products and nucleic acid bases. Chem. Res. Toxicol. 8(2), 278-283 (1995).

49 Koop DR. Oxidative and reductive metabolism by cytochrome $\mathrm{p} 4502 \mathrm{e} 1$. FASEB J. 6(2), 724-730 (1992).

50 Raucy JL, Kraner JC, Lasker JM. Bioactivation of halogenated hydrocarbons by cytochrome p4502e1. Crit. Rev. Toxicol. 23(1), 1-20 (1993).

51 Dan Z, Popov Y, Patsenker E et al. Hepatotoxicity of alcohol-induced polar retinol metabolites involves apoptosis via loss of mitochondrial membrane potential. FASEB J. 19(7), 845-847 (2005).

52 Liu C, Russell RM, Seitz HK, Wang XD. Ethanol enhances retinoic acid metabolism into polar metabolites in rat liver via induction of cytochrome $\mathrm{p} 4502 \mathrm{e} 1$. Gastroenterology 120(1), 179-189 (2001).

53 Wang XD, Liu C, Chung J, Stickel F, Seitz HK, Russell RM. Chronic alcohol intake reduces retinoic acid concentration and enhances ap-1 (c-jun and c-fos) expression in rat liver. Hepatology 28(3), 744-750 (1998).

54 Ye Q, Lian F, Chavez PR et al. Cytochrome p450 2e1 inhibition prevents hepatic carcinogenesis induced by diethylnitrosamine in alcohol-fed rats. Hepatobiliary Surg. Nutr. 1(1), 5-18 (2012). 
55 Lee HS, Yoon JH, Kamimura S, Iwata K, Watanabe H, Kim CY. Lack of association of cytochrome $\mathrm{p} 4502 \mathrm{e} 1$ genetic polymorphisms with the risk of human hepatocellular carcinoma. Int. J. Cancer 71(5), 737-740 (1997).

56 Steinmetz CG, Xie P, Weiner H, Hurley TD. Structure of mitochondrial aldehyde dehydrogenase: the genetic component of ethanol aversion. Structure 5(5), 701-711 (1997).

57 Brooks PJ, Theruvathu JA. DNA adducts from acetaldehyde: implications for alcohol-related carcinogenesis. Alcohol 35(3), 187-193 (2005).

- Review that addresses the contribution of alcohol metabolism and acetaldehyde production during the carcinogenic processes associated with chronic alcohol consumption. Provides detailed mechanistic insight into how acetaldehyde production directly contributes to the carcinogenic process.

58 Choi JY, Guengerich FP. Adduct size limits efficient and error-free bypass across bulky n2-guanine DNA lesions by human DNA polymerase eta. J. Mol. Biol. 352(1), 72-90 (2005).

59 De Los Santos C, Zaliznyak T, Johnson F. $\mathrm{Nmr}$ characterization of a DNA duplex containing the major acrolein-derived deoxyguanosine adduct gamma -oh-1,-n2propano-2'-deoxyguanosine. J. Biol. Chem. 276(12), 9077-9082 (2001).

60 Brooks PJ, Zakhari S. Acetaldehyde and the genome: beyond nuclear DNA adducts and carcinogenesis. Environ. Mol. Mutagen. 55(2), 77-91 (2014).

61 Freeman TL, Tuma DJ, Thiele GM et al. Recent advances in alcohol-induced adduct formation. Alcohol. Clin. Exp. Res. 29(7), 1310-1316 (2005).

62 Espina N, Lima V, Lieber CS, Garro AJ. In vitro and in vivo inhibitory effect of ethanol and acetaldehyde on o6-methylguanine transferase. Carcinogenesis 9(5), 761-766 (1988).

63 Sultana R, Bhupanapadu Sunkesula SR, Sharma V, Reddanna P, Babu PP. Formation of acetaldehyde adducts of glutathione $s$-transferase a 3 in the liver of rats administered alcohol chronically. Alcohol 35(1), 57-66 (2005).

64 Niemela O, Parkkila S, Yla-Herttuala S, Villanueva J, Ruebner B, Halsted CH. Sequential acetaldehyde production, lipid peroxidation, and fibrogenesis in micropig model of alcohol-induced liver disease.
Hepatology 22(4 Pt 1), 1208-1214 (1995).

65 Rolla R, Vay D, Mottaran E et al. Detection of circulating antibodies against malondialdehyde-acetaldehyde adducts in patients with alcohol-induced liver disease. Hepatology 31(4), 878-884 (2000).

66 Higuchi S, Matsushita S, Murayama M, Takagi S, Hayashida M. Alcohol and aldehyde dehydrogenase polymorphisms and the risk for alcoholism. A. J. Psychiatry 152(8), 1219-1221 (1995).

67 Yukawa Y, Muto M, Hori K et al. Combination of adh $1 b^{*} 2 /$ aldh $2 * 2$ polymorphisms alters acetaldehyde-derived DNA damage in the blood of japanese alcoholics. Cancer Sci. 103(9), 1651-1655 (2012).

68 Sakamoto T, Hara M, Higaki Y et al. Influence of alcohol consumption and gene polymorphisms of adh 2 and aldh 2 on hepatocellular carcinoma in a japanese population. Int. J. Cancer 118(6), 1501-1507 (2006).

69 Munaka M, Kohshi K, Kawamoto T et al. Genetic polymorphisms of tobacco- and alcohol-related metabolizing enzymes and the risk of hepatocellular carcinoma. J. Cancer Res. Clin. Oncol. 129(6), 355-360 (2003).

70 Portela A, Esteller M. Epigenetic modifications and human disease. Nat. Biotechnol. 28(10), 1057-1068 (2010).

71 Deaton AM, Bird A. Cpg islands and the regulation of transcription. Genes Dev. 25(10), 1010-1022 (2011).

72 Mato JM, Alvarez L, Ortiz P, Pajares MA. $\mathrm{S}$-adenosylmethionine synthesis: molecular mechanisms and clinical implications. Pharmacol. Ther. 73(3), 265-280 (1997).

73 Esfandiari F, Medici V, Wong DH et al. Epigenetic regulation of hepatic endoplasmic reticulum stress pathways in the ethanol-fed cystathionine beta synthase-deficient mouse. Hepatology 51(3), 932-941 (2010).

74 Jaenisch R, Bird A. Epigenetic regulation of gene expression: how the genome integrates intrinsic and environmental signals. Nat. Genet. 33(Suppl), 245-254 (2003).

75 Lee TD, Sadda MR, Mendler MH et al. Abnormal hepatic methionine and glutathione metabolism in patients with alcoholic hepatitis. Alcohol. Clin. Exp. Res. 28(1), 173-181 (2004).

76 Medici V, Halsted CH. Folate, alcohol, and liver disease. Mol. Nutr. Food Res. 57(4), 596-606 (2013).

-. Insightful and comprehensive review of the impact of chronic heavy alcohol intake on folate deficiency and the downstream impact of folate deficiency on the pathogenesis of alcoholic liver disease.

77 Barak AJ, Beckenhauer HC, Tuma DJ, Badakhsh S. Effects of prolonged ethanol feeding on methionine metabolism in rat liver. Biochem. Cell Biol. 65(3), 230-233 (1987).

78 Bonsch D, Lenz B, Fiszer R, Frieling H, Kornhuber J, Bleich S. Lowered DNA methyltransferase (dnmt-3b) mrna expression is associated with genomic DNA hypermethylation in patients with chronic alcoholism. J. Neural Transm. 113(9), 1299-1304 (2006).

79 Villanueva A, Portela A, Sayols S et al. DNA methylation-based prognosis and epidrivers in hepatocellular carcinoma. Hepatology 61(6), 1945-1956 (2015).

80 Calvisi DF, Ladu S, Gorden A et al. Mechanistic and prognostic significance of aberrant methylation in the molecular pathogenesis of human hepatocellular carcinoma. J. Clin. Invest. 117(9), 2713-2722 (2007).

81 Pascale RM, Simile MM, Satta G et al. Comparative effects of 1 -methionine, s-adenosyl-1-methionine and 5'-methylthioadenosine on the growth of preneoplastic lesions and DNA methylation in rat liver during the early stages of hepatocarcinogenesis. Anticancer Res. 11(4), 1617-1624 (1991).

82 Rambaldi A, Gluud C. S-adenosyl-1methionine for alcoholic liver diseases. Cochrane Database Syst. Rev.19(2), CD002235 (2006).

83 Bode C, Bode JC. Effect of alcohol consumption on the gut. Best Pract. Res. Clin. Gastroenterol. 17(4), 575-592 (2003).

84 Pande C, Kumar A, Sarin SK. Smallintestinal bacterial overgrowth in cirrhosis is related to the severity of liver disease. Aliment. Pharmacol. Ther. 29(12), 1273-1281 (2009).

85 Yan AW, Fouts DE, Brandl J et al. Enteric dysbiosis associated with a mouse model of alcoholic liver disease. Hepatology 53(1), 96-105 (2011).

86 Adachi Y, Moore LE, Bradford BU, Gao W, Thurman RG. Antibiotics prevent liver injury in rats following long-term exposure to ethanol. Gastroenterology 108(1), 218-224 (1995).

- Seminal experimental study linking chronic alcohol feeding to altered immune system function and the impact of this on alcohol-dependent liver disease.

87 Cederbaum AI. Microsomal generation of reactive oxygen species and their possible role 
in alcohol hepatotoxicity. Alcohol Alcohol. Suppl. 1, 291-296 (1991).

88 Nordmann R, Ribiere C, Rouach H. Implication of free radical mechanisms in ethanol-induced cellular injury. Free Radic. Biol. Med. 12(3), 219-240 (1992).

89 Husain K, Scott BR, Reddy SK, Somani SM Chronic ethanol and nicotine interaction on rat tissue antioxidant defense system. Alcohol 25(2), 89-97 (2001).

90 Fernandez-Checa JC, Kaplowitz N. Hepatic mitochondrial glutathione: transport and role in disease and toxicity. Toxicol. Appl. Pharmacol. 204(3), 263-273 (2005).

91 Cederbaum AI, Lu Y, Wu D. Role of oxidative stress in alcohol-induced liver injury. Arch. Toxicol. 83(6), 519-548 (2009).

92 Hoek JB, Pastorino JG. Cellular signaling mechanisms in alcohol-induced liver damage. Semin. Liver Dis. 24(3), 257-272 (2004).

93 Uesugi T, Froh M, Arteel GE, Bradford BU, Thurman RG. Toll-like receptor 4 is involved in the mechanism of early alcohol-induced liver injury in mice. Hepatology 34(1), 101-108 (2001).

94 Nagy LE. Recent insights into the role of the innate immune system in the development of alcoholic liver disease. Exp. Biol. Med. (Maywood) 228(8), 882-890 (2003).

-• Excellent, comprehensive overview of innate immune system responses in the onset and progression of alcoholic liver disease. Particular emphasis on Toll-like receptor signaling in Kupffer cells and how Kupffer cells interact with other hepatic cells in promoting the detrimental effects of alcohol.

95 Thakur V, Pritchard MT, McMullen MR, Wang Q, Nagy LE. Chronic ethanol feeding increases activation of nadph oxidase by lipopolysaccharide in rat kupffer cells: Role of increased reactive oxygen in lps-stimulated erk1/2 activation and tnf-alpha production. $J$. Leukoc. Biol. 79(6), 1348-1356 (2006).

96 Ramachandran P, Iredale JP. Macrophages: Central regulators of hepatic fibrogenesis and fibrosis resolution. J. Hepatol. 56(6), 1417-1419 (2012).

97 Urtasun R, Lopategi A, George J et al. Osteopontin, an oxidant stress sensitive cytokine, up-regulates collagen-i via integrin alpha(v)beta(3) engagement and pi3k/pakt/ nfkappab signaling. Hepatology 55(2), 594-608 (2012).

98 Singal AK, Jampana SC, Weinman SA. Antioxidants as therapeutic agents for liver disease. Liver Int. 31(10), 1432-1448 (2011).

99 Brandon-Warner E, Eheim AL, Foureau DM,
Walling TL, Schrum LW, Mckillop IH. Silibinin (milk thistle) potentiates ethanoldependent hepatocellular carcinoma progression in male mice. Cancer Lett. 326(1), 88-95 (2012).

100 Canto C, Auwerx J. Targeting sirtuin 1 to improve metabolism: all you need is $\operatorname{nad}(+)$ ? Pharmacol. Rev. 64(1), 166-187 (2012).

101 Nascimento AF, Ip BC, Luvizotto RA, Seitz HK, Wang XD. Aggravation of nonalcoholic steatohepatitis by moderate alcohol consumption is associated with decreased sirt 1 activity in rats. Hepatobiliary Surg. Nutr. 2(5), 252-259 (2013).

102 Lieber CS, Leo MA, Wang X, Decarli LM. Effect of chronic alcohol consumption on hepatic sirt1 and pgc-1alpha in rats. Biochem. Biophys. Res. Commun. 370(1), 44-48 (2008).

103 You M, Liang X, Ajmo JM, Ness GC. Involvement of mammalian sirtuin 1 in the action of ethanol in the liver. Am. J. Physiol. Gastrointest. Liver Physiol. 294(4), G892G898 (2008).

104 Yin H, Hu M, Liang X et al. Deletion of sirt1 from hepatocytes in mice disrupts lipin-1 signaling and aggravates alcoholic fatty liver. Gastroenterology 146(3), 801-811 (2014).

105 Ajmo JM, Liang X, Rogers CQ, Pennock B, You M. Resveratrol alleviates alcoholic fatty liver in mice. Am. J. Physiol. Gastrointest. Liver Physiol. 295(4), G833-G842 (2008).

106 Andrade JM, Paraiso AF, De Oliveira MV et al. Resveratrol attenuates hepatic steatosis in high-fat fed mice by decreasing lipogenesis and inflammation. Nutrition 30(7-8), 915-919 (2014).

107 Zheng Z, Chen H, Li J et al. Sirtuin 1-mediated cellular metabolic memory of high glucose via the $1 \mathrm{~kb} 1 / \mathrm{ampk} /$ ros pathway and therapeutic effects of metformin. Diabetes 61(1), 217-228 (2012).

108 Choi HN, Bae JS, Jamiyandorj U et al. Expression and role of sirt1 in hepatocellular carcinoma. Oncol. Rep. 26(2), 503-510 (2011).

109 Portmann S, Fahrner R, Lechleiter A et al. Antitumor effect of sirtl inhibition in human hcc tumor models in vitro and in vivo. Mol. Cancer Ther. 12(4), 499-508 (2013).

110 Jin J, Iakova P, Jiang Y et al. Transcriptional and translational regulation of c/ebpbetahdac1 protein complexes controls different levels of $\mathrm{p} 53$, sirt 1 , and pgclalpha proteins at the early and late stages of liver cancer. J. Biol. Chem. 288(20), 14451-14462 (2013).

111 Thompson KJ, Humphries JR, Niemeyer DJ, Sindram D, Mckillop IH. The effect of alcohol on sirt 1 expression and function in animal and human models of hepatocellular carcinoma (hcc). Adv. Exp. Med. Biol. 815, 361-373 (2015).

112 Jeong J, Juhn K, Lee $\mathrm{H}$ et al. Sirt1 promotes DNA repair activity and deacetylation of ku70. Exp. Mol. Med. 39(1), 8-13 (2007).

113 Herranz D, Munoz-Martin M, Canamero M et al. Sirt 1 improves healthy ageing and protects from metabolic syndrome-associated cancer. Nat. Commun. 1, 3 (2010).

114 Ponugoti B, Kim DH, Xiao Z et al. Sirt1 deacetylates and inhibits srebp-1c activity in regulation of hepatic lipid metabolism. J. Biol. Chem. 285(44), 33959-33970 (2010).

115 Clugston RD, Yuen JJ, Hu Y et al. Cd36deficient mice are resistant to alcohol- and high-carbohydrate-induced hepatic steatosis. J. Lipid Res. 55(2), 239-246 (2014).

116 Purohit V, Bode JC, Bode C et al. Alcohol, intestinal bacterial growth, intestinal permeability to endotoxin, and medical consequences: summary of a symposium. Alcohol 42(5), 349-361 (2008).

117 Cohen JI, Nagy LE. Pathogenesis of alcoholic liver disease: Interactions between parenchymal and non-parenchymal cells. J. Dig. Dis. 12(1), 3-9 (2011).

118 Lin CW, Lin CC, Mo LR et al. Heavy alcohol consumption increases the incidence of hepatocellular carcinoma in hepatitis b virus-related cirrhosis. J. Hepatol. 58(4), 730-735 (2013).

119 Calle EE, Rodriguez C, Walker-Thurmond K, Thun MJ. Overweight, obesity, and mortality from cancer in a prospectively studied cohort of u.S. Adults. N. Engl. J. Med. 348(17), 1625-1638 (2003).

120 Johnson NB, Hayes LD, Brown K, Hoo EC, Ethier KA. Cdc national health report: leading causes of morbidity and mortality and associated behavioral risk and protective factors-United States, 2005-2013. MMWR Surveill. Summ. 63(Suppl. 4), 3-27 (2014).

121 Dwyer-Lindgren L, Flaxman AD, Ng M, Hansen GM, Murray CJ, Mokdad AH. Drinking patterns in us counties from 2002 to 2012. Am. J. Public Health 105(6), 1120-1127 (2015).

122 Kim KR, Moon HE, Kim KW. Hypoxiainduced angiogenesis in human hepatocellular carcinoma. J. Mol. Med. (Berl.) 80 (11), 703-714 (2002).

123 Brandon-Warner E, Sugg JA, Schrum LW, Mckillop IH. Silibinin inhibits ethanol metabolism and ethanol-dependent cell proliferation in an in vitro model of hepatocellular carcinoma. Cancer Lett. 291(1), 
120-129 (2010).

124 Castaneda F, Kinne RK. Cytotoxicity of millimolar concentrations of ethanol on hepg2 human tumor cell line compared with normal rat hepatocytes in vitro. J. Cancer Res. Clin. Oncol. 126(9), 503-510 (2000).

125 Donohue TM, Osna NA, Clemens DL. Recombinant hep g2 cells that express alcohol dehydrogenase and cytochrome p450 2e1 as a model of ethanol-elicited cytotoxicity. Int. J. Biochem. Cell Biol. 38(1), 92-101 (2006).

126 Mckillop IH, Vyas N, Schmidt CM, Cahill PA, Sitzmann JV. Enhanced gi-proteinmediated mitogenesis following chronic ethanol exposure in a rat model of experimental hepatocellular carcinoma. Hepatology 29 (2), 412-420 (1999).

127 Thompson KJ, Swan RZ, Walling TL, Iannitti DA, Mckillop IH, Sindram D. Obesity, but not ethanol, promotes tumor incidence and progression in a mouse model of hepatocellular carcinoma in vivo. Surg. Endosc. 27(8), 2782-2791 (2013)

128 Wang F, Yang JL, Yu KK et al. Activation of the nf-kappab pathway as a mechanism of alcohol enhanced progression and metastasis of human hepatocellular carcinoma. Mol. Cancer 14(1), 10 (2015).

129 De Bruyn T, Chatterjee S, Fattah S et al. Sandwich-cultured hepatocytes: Utility for in vitro exploration of hepatobiliary drug disposition and drug-induced hepatotoxicity. Expert Opin. Drug Metab. Toxicol 9(5), 589-616 (2013).

130 Pfeiffer E, Kegel V, Zeilinger K et al. Featured article: Isolation, characterization, and cultivation of human hepatocytes and non-parenchymal liver cells. Exp. Biol. Med. (Maywood) 240(5), 645-656 (2015).

131 Bessems M, T Hart NA, Tolba R et al. The isolated perfused rat liver: standardization of a time-honoured model. Lab. Anim. 40 (3), 236-246 (2006).

132 Vickers AE, Fisher RL. Evaluation of drug-induced injury and human response in precision-cut tissue slices. Xenobiotica 43(1), 29-40 (2013).

133 Vickers AE, Fisher RL. Precision-cut organ slices to investigate target organ injury. Expert Opin. Drug Metab. Toxicol. 1(4), 687-699 (2005).

134 Duryee MJ, Willis MS, Schaffert CS et al.
Precision-cut liver slices from diet-induced obese rats exposed to ethanol are susceptible to oxidative stress and increased fatty acid synthesis. Am. J. Physiol. Gastrointest. Liver Physiol. 306(3), G208-G217 (2014).

135 Zhao P, Kalhorn TF, Slattery JT. Selective mitochondrial glutathione depletion by ethanol enhances acetaminophen toxicity in rat liver. Hepatology 36(2), 326-335 (2002).

136 Gallis JL, Serhan N, Gin H, Couzigou P, Beauvieux MC. Resveratrol plus ethanol counteract the ethanol-induced impairment of energy metabolism: (3)(1)p nmr study of atp and sn-glycerol-3-phosphate on isolated and perfused rat liver. Pharmacol. Res. 65(3), 387-395 (2012)

137 Brandon-Warner E, Schrum LW, Schmidt CM, Mckillop IH. Rodent models of alcoholic liver disease: of mice and men. Alcohol 46(8), 715-725 (2012).

-. Review that addresses established experimental models of alcohol feeding in vivo and their relative strengths and weaknesses as they relate to human pathology. Also discusses the emergence of newer models designed to overcome some of the limitations associated with established models.

138 Mathews S, Xu M, Wang H, Bertola A, Gao B. Animals models of gastrointestinal and liver diseases. Animal models of alcoholinduced liver disease: Pathophysiology, translational relevance, and challenges. Am. J. Physiol. Gastrointest. Liver Physiol. 306(10), G819-G823 (2014).

139 Bertola A, Mathews S, Ki SH, Wang H, Gao $B$. Mouse model of chronic and binge ethanol feeding (the niaaa model). Nat. Protoc. 8(3), 627-637 (2013).

-• Experimental description of a new model of chronic-binge alcohol feeding that exhibitis remarkably similar pathologies to human alcoholic liver disease in considerably shortened experimental time frames. This model is generating considerable interest in the field and is likely to become established as a well-used model to study a variety of pathologies and mechanisms associated with alcoholic liver disease.

140 Wang XW, Heegaard NH, Orum H. Micrornas in liver disease. Gastroenterology 142(7), 1431-1443 (2012).
141 Lakner AM, Bonkovsky HL, Schrum LW. Micrornas: Fad or future of liver disease. World J. Gastroenterol. 17(20), 2536-2542 (2011).

142 Mcdaniel K, Herrera L, Zhou T et al. The functional role of micrornas in alcoholic liver injury. J. Cell. Mol. Med. 18(2), 197-207 (2014).

143 Szabo G, Satishchandran A. Micrornas in alcoholic liver disease. Semin. Liver Dis. 35(1), 36-42 (2015).

144 Zeybel M, Hardy T, Robinson SM et al. Differential DNA methylation of genes involved in fibrosis progression in nonalcoholic fatty liver disease and alcoholic liver disease. Clin. Epigenetics 7(1), 25 (2015).

145 Shukla SD, Lim RW. Epigenetic effects of ethanol on the liver and gastrointestinal system. Alcohol Res. 35(1), 47-55 (2013).

146 Mandrekar P. Epigenetic regulation in alcoholic liver disease. World J. Gastroenterol. 17(20), 2456-2464 (2011).

147 Petrasek J, Csak T, Ganz M, Szabo G. Differences in innate immune signaling between alcoholic and non-alcoholic steatohepatitis. J. Gastroenterol. Hepatol. 28(Suppl. 1), 93-98 (2013).

148 Dixon LJ, Barnes M, Tang H, Pritchard MT, Nagy LE. Kupffer cells in the liver. Compr. Physiol. 3(2), 785-797 (2013).

149 Duddempudi AT. Immunology in alcoholic liver disease. Clin. Liver Dis. 16(4), 687-698 (2012).

150 Szabo G, Petrasek J, Bala S. Innate immunity and alcoholic liver disease. Dig. Dis. 30 (Suppl. 1), 55-60 (2012).

151 Mckillop IH. Alcohol and the brain-liver axis: a further case of mind over matter? Alcohol. Clin. Exp. Res. 39(3), 405-407 (2015).

152 Murugan S, Boyadjieva N, Sarkar DK. Protective effects of hypothalamic betaendorphin neurons against alcohol-induced liver injuries and liver cancers in rat animal models. Alcohol. Clin. Exp. Res. 38(12), 2988-2997 (2014).

153 Summa KC, Jiang P, Fitzpatrick K et al. Chronic alcohol exposure and the circadian clock mutation exert tissue-specific effects on gene expression in mouse hippocampus, liver, and proximal colon. Alcohol. Clin. Exp. Res. 39(10), 1917-1929 (2015). 